\title{
RECENT TRENDS IN BRAZILIAN MEDICAL RESEARCH. AN OVERVIEW
}

\author{
Mauricio Rocha-e-Silva
}

doi: 10.1590/S1807-59322009001000012

Rocha-e-Silva M. Recent trends in Brazilian medical research. An overview. Clinics. 2009;64(10):1007-13.

This article reviews 69 original research articles published in 6 Brazilian Medical Journals recently incorporated into the Institute for Scientific Information Journal of Citation Reports, with a view of making them comprehensively available to the readership of CLINICS within a subject category division. We expect this review to increase the visibility of a wide specter of original Brazilian research which may otherwise remain relatively unseen by the interested readership.

\section{INTRODUCTION}

Brazilian Medical Research is on the increase. However its visibility is still somewhat limited in spite of the enormous progress afforded by the institution of SciELO, the Electronic Scientific Library Online, which has gathered a collection of over 500 Latin American, Caribbean, and Iberian periodicals. The number of Brazilian Journals included in the Institute for Scientific Information Journal of Citation Reports has also increased significantly, but a number of newly included journals is still in the process of establishing a 3 year collection period which will enable them to have published impact factors. While this process is underway CLINICS has decided in conjunction with other Brazilian Medical Journals to make part of this collection of scientific reports available to its own readership. A systematic collection of original research articles from 6 of these Brazilian Journals is reviewed herein.

This review examines the papers appeared in Brazilian Medical Journals recently admitted to the Journal of Citation Reports database. The scope is to increase the visibility of such articles to the readership of CLINICS. Six Journals (Acta Ortopedica Brasileira, Arquivos Brasileiros de Cardiologia, Revista Brasileira de Cirurgia Cardíaca, Revista Brasileira de Medicina do Esporte, Revista da Associação

Hospital das Clínicas, Faculdade de Medicina da Universidade de São Paulo - São Paulo/SP, Brazil.

Email: mrsilva36@hcnet.usp.br

Tel.: 55113069.6235
Médica Brasileira, and São Paulo Medical Journal) were surveyed and papers published in the year 2007 were scanned for citations in the Journal of Citation Reports: Cited articles from each journal were selected and divided into subject categories.

A total 69 articles were selected and divided into 14 categories. In view of their multidisciplinary nature, some articles are included in more than one category. Categories and articles are as follows:

\section{Cardiovascular}

Under this general heading we detected the presence of articles on arterial disease, cardiac surgery, clinical cardiology and hypertension

Arterial Disease. Makdisse et al. ${ }^{1}$ evaluated a transcultural adaptation of a questionnaire on intermittent claudication, and conclude that the Brazilian Portuguese version of the Edinburgh claudication questionnaire maintained good sensitivity and specificity and can be recommended for screening of peripheral artery disease in clinical practice and epidemiological research in Brazil. Rocha et al. ${ }^{2}$ describe the hemodynamic behavior of arterial anastomosis using fibrin sealant in a porcine model, and conclude that this may reduce the number of required stitches.

Cardiac Surgery. Cardoso et al. ${ }^{3}$ found that the Amplatzer TM device for transcatheter closure of an ostium secundum atrial septal is an effective new development. Takiuti et al. ${ }^{4}$ evaluated the quality of life after myocardial 
revascularization and found improvement in all domains and in the three therapeutic modalities (clinical, stent placement and surgery). Comparatively, surgery however did provide a better quality of life after a four-year follow-up. Meireles et al. ${ }^{5}$ compared the effectiveness of diamond-like carbon coated stainless steel stent versus uncoated stent implantation in patients with coronary artery disease, but conclude that no better outcomes resulted from the use of the coated stent. Miana et al. ${ }^{6}$ discuss immediate results of right internal thoracic artery and radial artery as the second arterial graft in myocardial revascularization and find that the use of a Right Internal Thoracic Artery as a second arterial graft was associated with a prolonged operative time, but had no interference with the immediate clinical outcomes. Viaro et al. ${ }^{7}$, examined endothelial dysfunction caused by acute pressure distension of human Saphenous Vein used for myocardial revascularization and find that although vascular reactivity impairment was not demonstrated in vitro, the CD34 expression, measured by imunohistochemistry, shows there is endothelium dysfunction at pressures of $300 \mathrm{mmHg}$. Martins et al. ${ }^{8}$ constructed coronary artery bypasses using both Internal Mammary Arteries in patients with diabetes mellitus and find that such patients can benefit of double grafting, with little increase in risk for complications if its application is carefully indicated. Nery et al. ${ }^{9}$ described the influence of physical exercise in the outcome of myocardial revascularization and conclude that cardiac surgery promoted a modification of the habits of the patients increasing the number of physically active patients during a one year follow up. Avila Neto et al. ${ }^{10}$ surveyed the effect of temporary right atrial pacing in prevention of atrial fibrillation after coronary artery bypass graft surgery. They also find a reduced the incidence of atrial fibrillation after the surgery. Older age and non-atrial pacing were the independent predictive factors of the occurrence of this arrhythmia. Beani et al. ${ }^{11}$ discuss the use of late pulmonary tomography assessment in management of ductus arteriosum in premature infants with bronchopulmonary dysplasia, but find that the procedure is without influence on outcome. Silva et al. ${ }^{12}$ describe an experimental study on the use of a bicaval cannula for the approach of the pulmonary valve. Dinkhuysen et al. ${ }^{13}$ reports on the conception and development of a new spiral blood pump

General Clinical Cardiology. Souza et al. ${ }^{14}$ evaluated cardiac tissue adaptations in rats submitted to aerobic training after nitric oxide (NO) synthesis blockade and found that short term NO synthesis blockade in sedentary animals induced hypertension but did not cause cardiac hypertrophy. In the trained animals, the inhibition of NO synthesis attenuated hypertension, induced cardiac hypertrophy and significantly increased myocardial fibrosis, indicating that NO plays an important role in cardiac tissue adaptations caused by aerobic exercise. Ferreira et al. ${ }^{15}$ found that thermal dilution and trans-esophagic echodoppler yield comparative and reproducible measurements of cardiac output. Menezes Junior et al. ${ }^{16}$ showed that the combined effect of optimized atrial stimulation and atenolol is more effective in controlling recurrent atrial fibrillation. Esporcatte et al. ${ }^{17}$ showed that myeloperoxidase is highly effective in predicting high risk in patients with acute chest pain; Guerzoni et al. ${ }^{18}$ found that the TT genotype of the methyl$\mathrm{N}$-tetrahydrofolate reductase gene associates with more serious cases of coronary obstruction. while Villacorta et al. ${ }^{19}$ claim that C-reactive protein is an inflammatory marker with prognostic value in patients with decompensated heart failure. Nascimento et al. ${ }^{20}$ find that the midazolan was associated with a greater sedative and cardiovascular effect than diazepam in patients undergoing hemodynamic studies for suspected coronary artery disease. Issa et al..$^{21}$ found that bisoprolol was found to be safe and well tolerated in patients with heart failure, improved symptoms, hemodynamic variables, as well as the cardiac function for all etiologies of heart failure, but did not result in improved exercise capacity. Azevedo et al. ${ }^{22}$ described cardiac and metabolic characteristics of long distance runners.

Hypertension. Costa et al..$^{23}$, Jardim et al..$^{24}$ and Souza et al. ${ }^{25}$ evaluated prevalence of hypertension and its associated risk factors in adults: a population-based study in the major Brazilian cities, while Freitas et al. ${ }^{26}$ performed a combined analysis of genetic and environmental factors on essential hypertension in a Brazilian rural population in the Amazon region. Rosa et al. ${ }^{27}$ examined body mass index and waist circumference as markers of arterial hypertension in adolescents and found to be poorly sensitive markers. Silva et al. ${ }^{28}$ in contrast find that body overweight acted out as the only potential risk factor increasing arterial blood pressure in adolescents, irrespective of their sex and age. Cavalcante et al. ${ }^{29}$ quality of life of hypertensive patients treated at an outpatient clinic is not negatively affected because of the asymptomatic nature of the disease.

\section{Epidemiology and Public Health}

Apart from the previously described studies ${ }^{25,26}$ five other significant epidemiological studies were published. Glasberg et al. ${ }^{30}$ report that burnout is prevalent among Brazilian oncologists, but that oncologists having sufficient personal and social resources to engage in a hobby, physical activity, have enough vacation time and religious activities are at lower risk of developing burnout, Gawryszeski, et al. ${ }^{31}$ examined the prevalence of injury mortality and describe data which indicate a need to develop injury prevention strategies, considering the magnitude of the problem and 
the groups at high risk. Homicides among young people have to be addressed, while motor vehicle traffic injuries play an important role for all ages. Ângelo et al. ${ }^{32}$ determined echocardiographic reference values for cardiac chambers, left ventricular mass, and left ventricular mass indexes in an asymptomatic adult population sample and expect that results will be useful as a reference, since they are consistent with the new limits suggested in the literature for the echocardiographic diagnosis of left ventricular hypertrophy.

\section{Gastroenterology}

Bachella et al. ${ }^{33}$ compared the outcomes from marginal and non-marginal graft transplantation in 103 cases of liver transplantation due to chronic hepatic failure and found that marginal grafts increase early mortality in liver transplantation.

\section{Gynecology}

Ribeiro et al. ${ }^{34}$ report data that suggest that hysteroscopy is valuable as a diagnostic tool for malignant/hyperplastic and benign lesions, except for submucous myomas, for which the sensitivity was only $52.6 \%$.

\section{Immunology}

A study by Soares et al. ${ }^{35}$ on domestic allergens showed that the highest sensitization in allergic patients under study was to dust mites, especially Dermatophagoides pteronyssinus and Dermatophagoides farinae. They also note that the number of patients sensitized to cockroach extract was uncommonly high when compared to previous studies.

\section{Nephrology}

Taniguchi et al. ${ }^{36}$ reported that cardiopulmonary bypass time is a risk for renal failure, the greatest likelihood of developing kidney failure after heart surgery is observed when cardiopulmonary bypass time is at least 90 minutes, although creatinine clearance or mortality were not significantly different compared to lower duration procedures.

\section{Neurology}

Hirakawa et al. ${ }^{37}$ compared the effects of fibroblast growth factor and nerve fragments on tibial nerve regeneration in rats and found a higher amount of neurons on the side where the growth factor was used compared to the side where nervous fragments were placed, suggesting a superior performance of the fibroblast growth factor over nerve fragments for stimulating nervous regeneration. Braga Silva et al. ${ }^{38}$ described a new experimental model of spinal cord injury in rats with a device for local therapeutic agents access for the study of different modifiers of the regenerative response. Saba et al. ${ }^{39}$ describe the total absence of neuroprotective effects of diltiazem in rabbits with occluded aorta. Neuroprotective effects of diltiazen, Benício et al. ${ }^{40}$ compared ischemic preconditioning and cerebrospinal fluid drainage as methods of spinal cord protection in dogs and found that cerebrospinal fluid drainage and immediate ischemic preconditioning seem to protect the spinal cord during descending thoracic aorta cross-clamping. Nevertheless, spinal cord protection seems to be more significant with cerebrospinal fluid drainage.

\section{Nutrition}

A general and new development emerging from Brazilian nutritional research is the fact that obesity is gradually replacing malnutrition as the chief problem throughout the country. Barbosa et al. ${ }^{41}$ showed an association between nutritional status and functional capacity for elderly women in the city of São Paulo. Obesity was the nutritional condition associated with the worst performance in the tests. Nunes et al. ${ }^{42}$ find that overweight, obesity, excessive TV watching time, unhealthy feeding habits were observed across classes in the Northeastern Brazilian city of Campina Grande. Velásquez-Meléndez et al. ${ }^{43}$ found metabolic syndrome was also found to be prevalent in a rural community in the state of Minas Gerais. Karnikowski et al. ${ }^{44}$ describe non-alcoholic fatty liver disease and metabolic syndrome in a population of middle aged and older adults in Brasilia. Santos et al. ${ }^{45}$ examined the nutritional status, iron, copper, and zinc levels in school children of shantytowns of Sao Paulo and found to have low stature, with lower levels of malnutrition than of obesity, and anemia, which however was not associated to iron, copper or zinc deficits, As described above, body mass index and waist circumference were not found to be good markers of arterial hypertension in adolescents. ${ }^{27}$ In rats fed with a cholesterol rich diet, Paulo et al. ${ }^{46}$ found that total splenectomy caused a significant increase of cholesterol, LDL, VLDL and triglycerides.

\section{Oncology}

Trufelli et al ${ }^{47}$ evaluated the prognostic value of the ratio between positive and total dissected lymph nodes in patients with colon cancer who underwent primary tumor surgical resection and conclude that in the limited retrospective series studied, the ratio between positive and dissected 
lymph nodes was not independently associated with overall survival among patients. Battaglini et al. ${ }^{48}$ examined the effects of an individualized exercise intervention on body composition in breast cancer patients undergoing treatment and conclude that the results suggest that exercise emphasizing resistance training promotes positive changes in body composition and strength in breast cancer patients undergoing treatment., Saad et al. ${ }^{49}$ surveyed predictors of quality-of-life improvement following pulmonary resection due to lung cancer and found that the predictors that positively affected quality of life were better forced vital capacity, and six-minute walking test, as well as less extensive lung resection. Three months after the surgery, an improvement in social life was already seen.

\section{Orthopedics}

Nunes et al..$^{50}$ studied genetic and environmental factors involved on intervertebral disc degeneration and found a correlations between Fokl polymorphism, early degeneration, and intervertebral disc degeneration severity. Smoking habits were also found to interfere in this process, regardless of the presence or absence of a favorable genotype for glutathione transferase M1 and T1 genes. Oliveira et al. ${ }^{51}$ studied normal and degenerated intervertebral discs' mechanoreceptors of human lumbar spine through X-ray, magnetic resonance and pathoanatomy, finding (a) type-III fibers to be more common at the anterior region; (b) type-II and type-IV fibers more common at the posterior region, and (c) type-I fibers not to show any differences regarding anterior and posterior regions; in addition, degenerated discs have more nervous fibers than normal ones. , Rocha et al. ${ }^{52}$ reviewed 71 patients diagnosed with anterior cruciate ligament injury on 72 knees. The incidence of associated injuries (meniscal and joint cartilage injuries) were evaluated according to the time elapsed until ligament reconstruction. They observed a non-significant trend towards a higher number of meniscal injuries after 6 months, and of joint-cartilage injuries after 12 months since the primary anterior cruciate ligament injury. Rebelatto et al. ${ }^{53}$ studied general characteristics, determinant factors and relationship with handgrip strength of falls in institutionalized elderly people in the large provincial city of São Carlos, and found the incidence of falls and the individuals who were more likely to suffer falls were the older and weaker ones, as well as those unable to watch television. Franco et al..$^{54}$ performed an experimental study in fresh human cadavers to determine the resistance of osteosynthesis with plates and screws in anterior cervical spine fixation: three different types of plates (H-type Orozco's plate, conventional 1/3 tubular plate, plate described by Mendonça) were applied to segments of the cervical spine (C3-C7), and concludes that fixation with the $\mathrm{H}$ plate offers better stability when compared to other fixations and that the plates and screws used in the study decreased resistance when compared to an untreated control group. Fernandes et al..$^{55}$ compared back pain in patients with breast hypertrophy vs. normal sized breast and showed that back pain is more severe and determined more extensive limitations in the daily activities for patients presenting breast hypertrophy. Kirkwood et al. ${ }^{56}$ performed a biomechanical analysis of hip and knee joints during gait in elderly subjects, examining the range of motion, force momentum, power and the mechanical work performed by hip and knee joints in a group of subjects aged between 55 and 75 years, and conclude that biomechanical analysis of the joints during different activities would help clinicians to identify and understand important variables required for improving the performance and deficits of elderly individuals. Lustosa et al. ${ }^{57}$ compared muscular and functional performances, and passive joint laxity between volunteers who, after ligament reconstruction, returned to the same pre-injury activity level and those who did not. They found no differences between legs (operated and not operated) and conclude that passive joint laxity or muscular and functional performances cannot explain the return of the individuals to their same pre-injury functional level. Pizzato et al. ${ }^{58}$ analyzed of the medium frequency of the electromyographic signal of individuals with lesion of the anterior cruciate ligament in isometric exercises of open and closed kinetic chain. They found smaller medium frequency values in anterior cruciate ligament deficient subjects when compared with counter lateral and control groups in open kinetic exercises but no significant difference in closed kinetics exercises, and conclude that medium frequency can be considered an efficient tool in the anterior cruciate ligament injury characterization. Santos et al. ${ }^{59}$ compared integrated electromyographic ratio of the Vastus Medialis Obliquus and Vastus Lateralis Longus muscles in gait in subjects with and without patellofemoral pain syndrome and found that that the ratio of the electric activity of the Vastus Medialis and Vastus Lateralis muscles in individuals with and without patellofemoral pain syndrome is equal in the gait on flat surface as well as on a 5 degree-slanted surface. Vital et al..$^{60}$ examined the incidence of orthopedic trauma in parolympic athletes, and conclude that the increased intensity of training for such national and international events has led to an increase of this incidence. They also stress the importance of reinforcing the preventive measures to the athletes.

\section{Physical Exercise}

Apart from the papers describing the interactions of physical exercise with orthopedic pathologies described above, ${ }^{58-60}$ we highlight four other contributions. Sabbag et 
al. ${ }^{61}$ studied the effects of physical conditioning over patients with fibromyalgia, and found that work capacity improved from the third month pain threshold increased from the sixth month, post-exertion pain and number of tender points decreased in the ninth month, and pain intensity decreased in the twelfth month. Gama et al. ${ }^{62}$ studied the influence of the stretching frequency using proprioceptive neuromuscular facilitation in the flexibility of the hamstring muscles, and found that the stretching groups had a statistically significant range of motion gain in relation to the control group, Diefenthaeler et al..$^{63}$ compared absolute and relative physiological responses of cyclists and triathletes by measuring ventilatory threshold (an indicator of the lactate threshold) and maximal oxygen uptake during a bicycle ergometer test between cyclists and triathletes and found that the two groups showed different aerobic capacity because they have unlike physiological adaptations. Bertolla et al. ${ }^{64}$ evaluated the effects of a training program using the Pilates method upon the flexibility of sub-20 years indoor soccer athletes, finding acute effects, represented by a statistically significant immediate increase of flexibility and a chronic effect, with a non-significant trend to decline in the long run.

\section{Pneumology}

Romanini et al. ${ }^{65}$ analyzed the effects of intermittent positive pressure and incentive spirometry in the postoperative of myocardial revascularization, and found that the group submitted to incentive spirometry showed a significant increase in the maximum expiratory pressure 24 and 48 hours after surgery. They conclude that aiming at reversing hypoxemia earlier intermittent positive pressure was more efficient than inceptive spirometry, which however was more effective in improving respiratory muscle strength. Botter et al. ${ }^{66}$ described the surgical treatment of giant emphysematous lung bullae, and conclude that of the several surgical modalities were performed to treat the emphysematous lung bullae, drainage of the bullae with local anesthesia and sprayed talc should be the preferred modality. Krause et al. ${ }^{67}$ studied the influence of the level of physical activity over the cardiorespiratory capacity in older women, and found that, higher physical activity, especially higher sports physical activity, may attenuate the decrease of cardiorespiratory capacity in older women, suggesting that an increase of physical activities is recommended, especially regular physical exercises. Navarro et al. ${ }^{68}$ examined the effectiveness and safety of endotracheal tube cuffs filled with air versus filled with alkalinized lidocaine: a randomized clinical trial, and found that lidocaine filled cuffs prevented the occurrence of high cuff pressures during $\mathrm{N}_{2} \mathrm{O}$ anesthesia, reduced endotracheal discomfort and postoperative sore throat incidence.

\section{Sepsis}

Cicarelli et al ${ }^{69}$ performed a prospective randomized clinical trial on the effects of early dexamethasone treatment for septic shock patients, and showed that it reduced the seven-day mortality with a trend towards reduction of 28day mortality.

\section{REFERENCES}

1. Makdisse M, Nascimento Neto R, Chagas ACP, Brasil D, Borges JL, Oliveira A et al. .Cross-cultural adaptation and validation of the Brazilian Portuguese version of the Edinburgh Claudication Questionnaire. Arq. Bras. Cardiol. 2007;88:501-6.

2. Rocha EAV, Souza, C. Hemodinamic behavior of arterial anastomosis using fibrin sealant: experimental study in swine. Rev Bras Cir Cardiovasc. 2007;22: 81-6.

3. Cardoso CO, Rossi Filho RI, Machado PR, François LMG, Horowitz ESK, Sarmento-Leite R. Effectiveness of the Amplatzer TM device for transcatheter closure of an ostium secundum atrial septal defect. Arq. Bras. Cardiol. 2007;88:384-9.

4. Takiuti ME, Hueb W, Hiscock SB, Nogueira CRSR, Girardi P, Fernandes F et al. . Quality of life after surgical myocardial revascularization, angioplasty or medical treatment. Arq. Bras. Cardiol. 2007;88: 537-44.

5. Meireles GCX, Abreu LM, Forte AAC, Sumita MK, Sumita JH, Aliaga JDCS. Randomized comparative study of diamond-like carbon coated stainless steel stent versus uncoated stent implantation in patients with coronary artery disease. Arq. Bras. Cardiol. 2007;88:390-5.
6. Miana LA, Lima DS, Whitaker JF, Passos PHC, Loures JBL, Miana AA. Immediate results of right internal thoracic artery and radial artery as the second arterial graft in myocardial revascularization. Rev Bras Cir Cardiovasc. 2007;22:60-7.

7. Viaro F, Carlotti Jr CG, Rodrigues AJ, Vicente WVA, Bassetto S, Reis GS et al. . Endothelium dysfunction caused by acute pressure distension of human saphenous vein used for myocardial revascularization. Rev Bras Cir Cardiovasc. 2007;22:169-175.

8. Martins SK, Santos MA, Tirado FHP, M Jr FCE, Malat HF, Jatene AD et al. .Coronary artery bypass grafting using both internal mammary arteries in patients with diabetes mellitus. Rev Bras Cir Cardiovasc. 2007;22:291-6

9. Nery RM, Barbisan JN, Mahmud MI. Influence of the practice physical activity in the coronary artery bypass graft surgery results. Rev Bras Cir Cardiovasc. 2007;22:297-302.

10. Avila Neto V, Costa R, Silva KR, Martins ALM, Moreira LFPinho, Santos LB et al. .Effect of temporary right atrial pacing in prevention of atrial fibrillation after coronary artery bypass graft surgery. Rev Bras Cir Cardiovasc. 2007;22:332-40. 
11. Beani L, Moscardini AC, Souza AS, Souza Jr AS, Yamamoto AE, Croti UA et al. . Late pulmonary tomography assessment in premature infants with bronchopulmonary dysplasia submitted to patent ductus arteriosus management. Rev Bras Cir Cardiovasc. 2007;22: 400-406.

12. Silva AMRP, Dallan LAP, Campagnucci VP, Caruso J, Gandra SMA, Rivetti LA. Approach of the pulmonary valve using right heart bypass and bicaval cannula: experimental study. Rev Bras Cir Cardiovasc. 2007;22:463-9.

13. Dinkhuysen JJ, Andrade AJP, Manrique R, Saito CSM, Leme J, Biscegli F. Spiral blood pump: conception, development and clinical application of the original project. Rev Bras Cir Cardiovasc. 2007;22:218-23.

14. Souza HCD, Penteado DMD, Martin-Pinge MC, Barbosa Neto O, Teixeira VPA, Blanco JHD et al. . Nitric oxide synthesis blockade increases hypertrophy and cardiac fibrosis in rats submitted to aerobic training. Arq. Bras. Cardiol. 2007;89:99-104.

15. Ferreira RMV, Amaral JLG, Valiatti JLS. Comparação dos valores de débito cardíaco obtidos por termodiluição e dopplerfluxometria transesofágica. [Comparison between two methods for hemodynamic measurement: thermodilution and oesophageal Doppler]. Rev. Assoc. Med. Bras. 2007;53:349-54.

16. Menezes Júnior AS, Martinelli Filho M, Menezes CCS, Costa R, Ramires JAF. Effects of the association of dual-site dynamic atrial overdrive and atenolol in preventing recurrent atrial fibrillation. Arq. Bras. Cardiol. 2007;88:1-7.

17. Esporcatte R, Rey HCV, Rangel FOD, Rocha RM, Mendonça Filho HTF, Dohmann HFRet al. . Predictive value of myeloperoxidase to identify high risk patients admitted to the hospital with acute chest pain. Arq. Bras. Cardiol. 2007;89:377-84

18. Guerzoni AR, Pavarino-Bertelli EC, Godoy MF, Graça CR, Biselli PM, Souza DRS et al. . Methylenetetrahydrofolate reductase gene polymorphism and its association with coronary artery disease. Sao Paulo Med. J. 2007;125:4-8.

19. Villacorta H, Masetto AC, Mesquita ET. C-reactive protein: an inflammatory marker with prognostic value in patients with decompensated heart failure. Arq. Bras. Cardiol. 2007;88:585-9.

20. Nascimento JS, Modolo NSP, Silva RCR, Santos KP, Carvalho HG. Sedative and cardiovascular effects of midazolam and diazepam alone or combined with clonidine in patients undergoing hemodynamic studies for suspected coronary artery disease. Arq. Bras. Cardiol. 2007;89:403-8.

21. Issa VS, Guimarães GV, Rezende MVC, Cruz FD, Ferreira SMA, Bacal F et al. . Effects of bisoprolol on cardiac function and exercise in patients with heart failure. Arq. Bras. Cardiol. 2007;88:340-5.

22. Azevedo LF, Brum PC, Rosemblatt D, Perlingeiro PS, Barretto ACP, Negrão CE et al. . Cardiac and metabolic characteristics in long distance runners of sport and exercise cardiology outpatient facility of a tertiary hospital. Arq. Bras. Cardiol. 2007;88:17-25.

23. Costa JSD, Barcellos FC, Sclowitz ML, Sclowitz IKT, Castanheira M, Olinto MTA et al. . Hypertension prevalence and its associated risk factors in adults: a population-based study in Pelotas. Arq. Bras. Cardiol. 2007;88:59-65.

24. Jardim PCBV, Gondim MRP, Monego ET, Moreira HG, Vitorino PVO, Souza WKSB et al. . High blood pressure and some risk factors in a Brazilian capital. Arq. Bras. Cardiol. 2007;88:452-7.
25. Souza ARA, Costa A, Nakamura D, Mocheti LN, Stevanato Filho PR, Ovando LA. A study on systemic arterial hypertension in Campo Grande, MS, Brazil. Arq. Bras. Cardiol. 2007;88:441-6.

26. Freitas SRS, Cabello PH, Moura-Neto RS, Dolinsky LC, Bóia MN Combined analysis of genetic and environmental factors on essential hypertension in a Brazilian rural population in the Amazon region. Arq. Bras. Cardiol. 2007;88:447-51.

27. Rosa MLG, Mesquita ET, Rocha ERR, Fonseca VM. Body mass index and waist circumference as markers of arterial hypertension in adolescents. Arq. Bras. Cardiol. 2007;88:573-8.

28. Silva KS, Farias Júnior JC. Risk factors associated with high blood pressure in adolescents. Rev Bras Med Esporte. 2007;13:237-40.

29. Cavalcante MA, Bombig MTN, Luna Filho B, Carvalho ACC, Paola AAV, Póvoa R. Quality of life of hypertensive patients treated at an outpatient clinic. Arq. Bras. Cardiol. 2007;89:245-50.

30. Glasberg J Horiuti L, Novais MAB, Canavezzi AZ, Miranda VC, Chicoli FA et al. . Prevalence of the burnout syndrome among Brazilian medical oncologists. Rev. Assoc. Med. Bras. 2007;53:85-9.

31. Gawryszeski, VP. Injury mortality report for São Paulo State, 2003. Sao Paulo Med. J. 2007;125:139-43.

32. Ângelo LCS, Vieira MLC, Rodrigues SL, Morelato RL, Pereira AC., Mill JG et al. . Echocardiographic reference values in a sample of asymptomatic adult Brazilian population. Arq. Bras. Cardiol. 2007;89:184-90

33. Bacchella T, Galvão FHF, Almeida JLJ, Figueira ER, Moraes A, Machado MCC. Marginal grafts increase early mortality in liver transplantation. Sao Paulo Med. J. 2008;126:161-5.

34. Ribeiro CT, Rosa-e-Silva JC, Silva-de-Sá MF, Rosa-e-Silva ACJS, Poli Neto OB, Reis FJC et al. . Hysteroscopy as a standard procedure for assessing endometrial lesions among postmenopausal women. Sao Paulo Med. J. 2007;125:338-42.

35. Soares FAA, Segundo GRS, Alves R, Ynoue LH, Resende RO, Sopelete MC et al. . Perfil de sensibilização a alérgenos domiciliares em pacientes ambulatoriais. [Indoor allergen sensitization profile in allergic patients of the allergy clinic in the University Hospital in Uberlândia, Brazil]. Rev. Assoc. Med. Bras. 2007;53:25-8.

36. Taniguchi FP, Souza AR, Martins AS. Cardiopulmonary bypass time as a risk factor for acute renal failure. Rev Bras Cir Cardiovasc. 2007;22:2015 .

37. Hirakawa CK, Grecco MAS, Santos JBG, Leite VM, Faloppa F. Fibroblasts growth factor and nerve fragments effect on tibial nerve regeneration in rats: a comparative study. Acta Ortop Bras. 2007;15:114-

38. Braga-Silva J, Gehlen D, Roman JA, Machado DC, Costa JC, Faúndez $\mathrm{M}$ et al. . Experimental model of spinal cord injury in rats with a device for local therapeutic agents access. Acta Ortop Bras. 2007;15:155-7.

39. Saba T, Manduz S, Sapmaz I, Tunel A, Aker H, Dogan K. Neuroprotective effects of diltiazem in rabbits with occluded aorta. Rev Bras Cir Cardiovasc. 2007;22:416-24.

40. Benício A, Moreira LFP, Mônaco BA, Castelli JB., Mingrone LE, Stolf NAG. Comparative study between ischemic preconditioning and cerebrospinal fluid drainage as methods of spinal cord protection in dogs. Rev Bras Cir Cardiovasc. 2007;22:15-23. 
41. Barbosa AR, Souza JMP, Lebrão ML, Marucci MFN. Estado nutricional e desempenho motor de idosos de São Paulo. [Nutritional status and physical performance of elderly in the city of São Paulo]. Rev. Assoc. Med. Bras. 2007;53:75-9.

42. Nunes MMA, Figueiroa JN, Alves JGB. Excesso de peso, atividade física e hábitos alimentares entre adolescentes de diferentes classes econômicas em Campina Grande (PB). [Overweight, physical activity and foods habits in adolescents from different economic levels, Campina Grande (PB)]. Rev. Assoc. Med. Bras. 2007;53:130-4.

43. Velásquez-Meléndez G, Gazzinelli A, Côrrea-Oliveira R, Pimenta AM, Kac G. Prevalence of metabolic syndrome in a rural area of Brazil. Sao Paulo Med. J. 2007;125:155-62.

44. Karnikowski M, Córdova C, Oliveira RJ, Karnikowski MGO, Nóbrega OT. Non-alcoholic fatty liver disease and metabolic syndrome in Brazilian middle-aged and older adults. Sao Paulo Med. J. 2007;125:3337.

45. Santos EB, Amancio OMS, Oliva CAG. Estado nutricional, ferro, cobre e zinco em escolares de favelas da cidade de São Paulo. [Nutritional status, iron, copper, and zinc in school children of shantytowns of Sao Paulo]. Rev. Assoc. Med. Bras. 2007;53:323-8.

46. Paulo ICAL, Paulo DNS, Kalil M, Guerra AJ, Guerzet EA, Silva AL. Lípides plasmáticos em ratos após cirurgia esplênica - efeito de dois tipos de dieta. [Effects of two types of diet on plasma lipids in rats submitted to splenic surgery]. Rev. Assoc. Med. Bras. 2007;53:171-7.

47. Trufelli DC, Miranda VC, Palos CC, Ramos E, Abrão MN, Silva VA et al. . Razão entre linfonodos positivos e dissecados como fator prognóstico em câncer de cólon. [Positive / Total dissected lymph nodes ratio as a prognostic factor in colon cancer]. Rev. Assoc. Med. Bras. 2007;53:53942 .

48. Battaglini C, Bottaro M, Dennehy C, Rae L, Shields E, Kirk D. The effects of an individualized exercise intervention on body composition in breast cancer patients undergoing treatment. Sao Paulo Med. J. 2007;125:22-8.

49. Saad IAB, Botega NJ, Toro IFC. Predictors of quality-of-life improvement following pulmonary resection due to lung cancer. Sao Paulo Med. J. 2007;125:46-9.

50. Nunes FTB, Conforti-Froes NDT, Negrelli WF, Souza DRS. Genetic and environmental factors involved on intervertebral disc degeneration. Acta Ortop Bras. 2007;15:9-13.

51. Oliveira VM, Puertas EB, Alves MTS, Yamashita HK. Comparative study of normal and degenerated intervertebral discs' mechanoreceptors of human lumar spine X-ray, magnetic resonance and anatomopathologic study. Acta Ortop Bras. 2007;15:35-9.

52. Rocha ID, Moraes TMS, Rezende MU, Pécora JR. Progress assessment of injuries associated to anterior cruciate ligament injuries. Acta Ortop Bras. 2007:15:105-8.

53. Rebelatto JR, Castro AP, Chan A. Falls in institutionalized elderly people: general characteristics, determinant factors and relationship with handgrip strength. Acta Ortop Bras. 2007;15:151-4.

54. Franco JS, Machado IR, Oliveira RP, Cristante AF, Leivas TP, Marcon $\mathrm{RM}$ et al. . Resistance of osteosyntheses with plates and screws in anterior cervical spine fixation: an experimental study. Acta Ortop Bras. 2007;15:191-6.
55. Fernandes PM, Sabino Neto M, Veiga DF, Abla LEF, Mundim CDA, Juliano Y et al. . Back pain: an assessment in breast hypertrophy patients. Acta Ortop Bras. 2007;15:227-30.

56. Kirkwood RN, Gomes HA, Sampaio RF, Culham E, Costigan P. Biomechanical analysis of hip and knee joints during gait in elderly subjects. Acta Ortop Bras. 2007;15:267-71.

57. Lustosa LP, Fonseca ST, Andrade MAP. Reconstruction of the anterior cruciate ligament: impact of muscular and functional performances on the return to pre-injury activity level. Acta Ortop Bras. 2007;15:280-4.

58. Pizzato LM, Arakaki JC, Vasconcelos RA, Sposito GC, Oliveira AS, Paccola CJ et al. . Analysis of the medium frequency of the electromyographic signal of individuals with lesion of the anterior cruciate ligament in isometric exercises of open and closed kinetic chain. Rev Bras Med Esporte. 2007;13:1-5.

59. Santos GM, Say KG, Pulzato F, Oliveira AS, Bevilaqua-Grossi D, Monteiro-PV. Integrated electromyographic ratio of the vastus medialis oblique and vastus lateralis longus muscles in gait in subjects with and without patellofemoral pain syndrome. Rev Bras Med Esporte. 2007;13:17-21.

60. Vital R, Silva HGPV, Sousa RPA, Nascimento RB, Rocha EA, Miranda HF et al. . Orthopaedic trauma injuries in paralympic athletes. Rev Bras Med Esporte. 2007;13:165-8.

61. Sabbag LMS, Pastore CA, Yazbek Júnior P, Miyazaki MH, Gonçalves A, Kaziyama HHS et al. . Effects of physical conditioning over patients with fibromyalgia. Rev Bras Med Esporte. 2007;13: 6-10.

62. Gama ZAS, Medeiros CAS, Dantas AVR, Souza TO. Influence of the stretching frequency using proprioceptive neuromuscular facilitation in the flexibility of the hamstring muscles. Rev Bras Med Esporte. 2007; $13: 33-8$

63. Diefenthaeler F, Candotti CT, Ribeiro J, Oliveira AR. Comparison of absolute and relative phisiological responses of cyclists and triathletes. Rev Bras Med Esporte. 2007;13:205-8.

64. Bertolla F, Baroni BM, Leal Junior ECP, Oltramari JD. Effects of a training program using the Pilates method in flexibility of sub-20 indoor soccer athletes. Rev Bras Med Esporte. 2007;13:222-6.

65. Romanini W, Muller AP, Carvalho KAT, Olandoski M, Faria-Neto JR, Mendes FL et al. . The effects of intermittent positive pressure and incentive spirometry in the postoperative of myocardial revascularization. Arq. Bras. Cardiol. 2007;89:105-10.

66. Botter M, Saad Júnior R, Botter DA, Rivabem JH, Gonçalves R, Dorgan Neto V. Tratamento operatório das bolhas pulmonares gigantes. [Surgical treatment of giant emphysematous lung bullae]. Rev. Assoc. Med. Bras. 2007;53:217-22.

67. Krause MP, Buzzachera CF, Hallage T, Pulner SB, Silva SG. Influence of the level of physical activity over the cardiorespiratory capacity in older women. Rev Bras Med Esporte. 2007;13:97-102.

68. Navarro LHC, Braz JRC, NG, Lima RM, Silva FP, Módolo NSP. Effectiveness and safety of endotracheal tube cuffs filled with air versus filled with alkalinized lidocaine: a randomized clinical trial. Sao Paulo Med J. 2007;125:322-8.

69. Cicarelli DD, Vieira JE, Bensenor, FEM. Early dexamethasone treatment for septic shock patients: a prospective randomized clinical trial. Sao Paulo Med. J. 2007;125:237-41. 
